\title{
Using Organigraphs to Map Disaster Risk Management Governance in the Field of Cultural Heritage
}

\author{
Louis J. Durrant ${ }^{1, * \mathbb{C}}$, Atish N. Vadher ${ }^{2}$, Mirza Sarač ${ }^{3}{ }^{\mathbb{C}}$, Duygu Başoğlu $^{4}$ and Jacques Teller ${ }^{1} \mathbb{C}$ \\ 1 LEMA Research Group, Urban \& Environmental Engineering Department, University of Liège, \\ 4000 Liège, Belgium; Jacques.Teller@uliege.be \\ 2 Faculty of Arts, Science and Technology, University of Northampton, Northampton NN1 5PH, UK; \\ Atish.Vadher@northampton.ac.uk \\ 3 International Sava River Basin Commission (ISRBC), Kneza Branimira 29/II, 10000 Zagreb, Croatia; \\ msarac@savacommission.org \\ 4 Ekodenge A.S, Hacettepe Teknokent, 1.Ar-Ge Binası, No. 18, Ankara 06800, Turkey; \\ duygu.basoglu@ekodenge.com \\ * Correspondence: louis.durrant@uliege.be; Tel.: +32-470-51-84-07
}

check for updates

Citation: Durrant, L.J.; Vadher, A.N.; Sarač, M.; Başoğlu, D.; Teller, J. Using Organigraphs to Map Disaster Risk Management Governance in the Field of Cultural Heritage. Sustainability 2022, 14, 1002. https://doi.org/ $10.3390 /$ su14021002

Academic Editors: Leire Garmendia, Alessandra Gandini and Gemma Garcia Blanco

Received: 9 December 2021

Accepted: 12 January 2022

Published: 17 January 2022

Publisher's Note: MDPI stays neutral with regard to jurisdictional claims in published maps and institutional affiliations.

Copyright: (C) 2022 by the authors. Licensee MDPI, Basel, Switzerland. This article is an open access article distributed under the terms and conditions of the Creative Commons Attribution (CC BY) license (https:// creativecommons.org/licenses/by/ $4.0 /)$.

\begin{abstract}
Global cultural heritage is threatened by the increasing frequency and severity of natural disasters caused by climate change. International experts emphasise the importance of managing cultural heritage sustainably as part of a paradigm shift in cultural heritage perception, understanding, and management. This paradigm shift has stimulated a need to integrate cultural heritage into preexisting disaster risk management governance. However, there is currently a lack of robust and practical approaches to map the complex nature of disaster risk management governance. It is here considered that a shared understanding of the respective roles and responsibilities of the different organisations involved in risk management is a critical element in improving the preparedness of cultural heritage sites. The purpose of this article is to present the utility of the Organigraph technique and its main components as a tool to map governance structures, identify key stakeholders, and integrate cultural heritage experts into wider disaster risk management. The article presents a semi-empirical research approach, consisting of four iterative phases in which a series of digital workshops, semi-structured meetings, and bilateral expert meetings were used to co-produce five Organigraphs for heritage sites participating in an ongoing European Project. Our findings suggest that Organigraphs provide a valuable tool at the disposal of practitioners and academics with the potential to provide a basis for cross-national, cross-issue, and cross-scale peer learning between heritage sites. Furthermore, the technique is a valuable self-diagnostic tool to facilitate learning and proactive discussions in the preparedness phase of disaster risk management. Finally, they facilitate the co-creation of solutions through an evolving, interactive platform to integrate datadriven approaches.
\end{abstract}

Keywords: governance; mapping; Organigraph; cultural heritage; stakeholders and disaster risk management

\section{Introduction}

There is an ongoing paradigm shift within the cultural heritage $(\mathrm{CH})$ discourse [1-3]. This shift has, in part, been stimulated by the perceived vulnerability of the worlds $\mathrm{CH}$ to the increasing frequency and severity of natural disasters driven by the effects of climate change [4,5]. One key aspect of research within this broader paradigm shift focuses upon the theoretical and operational integration of $\mathrm{CH}$ into the concepts of sustainability and resilience [6-9]. One aspect of which is the mutually beneficial integration of $\mathrm{CH}$ into disaster risk management (DRM) and its ability to enhance the resilience of $\mathrm{CH}[10,11]$. Within this shifting paradigm, international institutions such as UNESCO, ICCROM, and 
ICOMOS have been powerful driving forces publishing a variety of frameworks, white papers, reports, and reviews to facilitate this paradigm shift.

Crucially, a framework championed to aid in the operationalisation of $\mathrm{CH}$ into DRM is The Sendai Framework for Disaster Risk Reduction (SFDRR) [12]. The SFDRR aims to substantially reduce disaster risk and losses in lives, livelihoods, and health and the economic, physical, social, cultural, and environmental assets of persons, businesses, communities, and countries over the next 15 years [13]. As well as a change in DRM thinking from what one scholar nicely summarises as "a shift from reaction to prevention" [14]. Notably, this shift explicitly recognises the importance and role of CH in DRM. It attempts to reduce overall disaster risk to those $\mathrm{CH}$ sites [12], in which contemporary scholars are exploring the integration of $\mathrm{CH}$ into the broader concept of DRM both conceptually [15] and practically $[16,17]$.

This article focuses on the practical aspects of this integration, especially the operationalisation of the SFDRR. Priority 2 is entitled "Strengthening disaster risk governance to manage disaster risk" [13], which focuses on the importance of effective and efficient management of disaster risk as well as clear visions, plans, competencies, guidance, coordination within and across sectors, and, finally, the participation of relevant stakeholder groups. These priorities explicitly focus on the role of governance in DRM and disaster risk reduction (DRR) to enhance resilience within $\mathrm{CH}$ sites and beyond [18].

Critically, effective, and efficient governance is cited as a potential avenue for risk reduction [19-21]. Furthermore, contemporary research has emphasised the importance of governance to enhance the risk management capabilities of countries and the institutions responsible for DRM [22]. Finally, researchers also emphasise the need for robust governance mechanisms at multiple spatial scales in DRM and CH conservation [23,24]. This avenue of research provides clear links between the importance of governance and effective DRM and DRR strategies and the role of governance in enhancing $\mathrm{CH}$ resilience. However, international scholars have been critical of the uptake of the SFDRR into practice since its conception in 2015 [14,25,26]. Of relevance is the research by Djalante and Lassa [18], in which they explore the complexities and challenges of integrating the SFDRR into DRR governance. These scholars highlight the importance of governance to effective DRR and the theoretical and practical challenges (and opportunities) of integrating $\mathrm{CH}$ and DRM. To briefly explore these challenges, $\mathrm{CH}$ often represents a broader range of subjective values bringing together very different and potentially conflicting perspectives, experiences, and attachments $[2,27,28]$. As a result, the governance of $\mathrm{CH}$ sites typically involves many stakeholders [29,30] with varying values [31] and intersubjective perceptions [28]. The safeguarding of such values can be challenging within the overall context of risk reduction and associated strategies [6].

Secondly, the governance within the management of $\mathrm{CH}$ is often implicit. Scholars highlight that there are often no stabilised legal or regulatory frameworks at the national level that encompass $\mathrm{CH}$ issues into DRM [10]. Building upon this, from our practical experience in the ongoing European project, some decision-making processes behind $\mathrm{CH}$ often embraces more implicit and adaptive governance approaches, not defined by pre-existing legal frameworks but still critical to the effective conservation and management of $\mathrm{CH}$ sites. On the one hand, the role of non-traditional management and governance approaches in implementing the SFDRR may provide many benefits in the event of disasters [32]. However, on the other hand, the lack of non-traditional management and governance approaches can make it challenging to develop explicit clarity around DRM governance within $\mathrm{CH}$. Not only do these challenges potentially exacerbate the difficulties in operationalising the SFDRR, but they complicate the enhancement of resilience of $\mathrm{CH}$ sites in the event of a disaster. These broader issues are of paramount importance when considering the need to build trust between distinct stakeholder groups and the government before disaster events [33]. Finally, taking this one step further, from a broader perspective, academic literature highlights the importance of preparedness in the effective response and recovery of disasters [34] as well as the economic benefits of investing in disaster preparedness [35-37]. 
In conclusion, there is a pressing need for experts, academics, and policymakers to improve our critical understanding of one's governance structure and possible limitations, vulnerabilities, and weaknesses. It may address some of the challenges of operationalising the SFDRR into practice through enhancing clarity, trust, and understanding of DRM governance and encourage stakeholders to pro-actively critique the preparedness of their DRM governance structure, ultimately leading to better response and mitigation of DRM, conserving $\mathrm{CH}$.

In response, we tested the use of the Organigraph technique as a tool to co-produce detailed DRM governance maps for $\mathrm{CH}$ sites. Organigraphs facilitates the development of clarity and a shared understanding of the DRM governance structures between different stakeholders by pinpointing who is involved, how they make decisions and interact, and what reinforces those mechanisms and reinforces those decisions. This article presents a semi-empirical research approach used to co-produce detailed DRM governance maps within the context of three $\mathrm{CH}$ sites across Europe. This approach is based upon the Organigraph technique initially developed by Mintzberg and Van der Heyden [38] and inspired by the recent application of the technique in the context of governance [39]. First, this research article outlines the steps of the approach and supporting material used to co-produce the Organigraphs in collaboration with practitioners. This is followed by three example Organigraphs that have been actively co-produced by three international Living Labs (LL) over a two-year period.

This article aims to highlight the potential value of the Organigraph technique as a tool to map DRM governance in the context of $\mathrm{CH}$ by drawing upon its application and the preliminary findings within an ongoing European research project, in which the tool has the capacity to explicitly outline the clarity and competence between different stakeholder groups. Furthermore, the article explores the potential value of the semi-empirical approach in providing a basis for cross-national, cross-issue, and cross-scale peer learning between heritage sites and a valuable self-diagnostic tool within existing governance structures to facilitate proactive discussions before a disaster event. Finally, this article will highlight the value of the Organigraph technique to academics, policymakers, and practitioners, forming the basis for further research into the value and application of the Organigraph technique as a decision support tool at the disposal of DRM stakeholders.

\section{Materials and Methods}

The Organigraphs within this article were co-produced using an innovative and collaborative semi-empirical approach, bringing together the knowledge, expertise, and perceptions of transdisciplinary stakeholders. The entire semi-empirical approach was undertaken from August 2020 until September 2021 and comprised of four iterative phases. It is important to note that this timeline included the development of five Organigraphs simultaneously from five different Living Labs (LL) participating as interactive case studies across Europe. Each of the four iterative phases serves a specific function and consists of separated methodological approaches, all outlined in Figure 1.

Phase 1 commenced in August 2020 and ran until November 2020 and focused on the consolidation of relevant pre-existing material within each LL before formal information requests were made to the Living Lab coordinators (LLC). The LLC formed the main focal point for each LL, serving as a critical interface between the local stakeholder groups and the research team. Furthermore, the LLCs were instrumental in developing and drafting the Organigraphs alongside the researcher. While there were no specific criteria to refine the material consolidation, the researcher focused on sources that referred to specific stakeholder groups, their relationships, and/or material that referred to governance mechanisms (strategies, laws, legislation, policies, or plans, etc.). A variety of different information sources were collected and provided valuable insights, including but not limited to published and unpublished research articles, students' thesis, LL websites, news articles, and data from other EU projects. Following the consolidation of any pre-existing raw material, the research sent refined information requests to LLC through email or digital 
meetings to gather any missing or unpublished information that may add to the drafting of the preliminary Organigraphs. Finally, following the consolidation of existing material and any subsequent material forwarded by the LLC, draft Organigraphs were co-created by the researcher and the LLC using a standardised key inspired by and adapted from the preliminary guidelines outlined by Tiliouine et al. [39]. Encapsulated in Figure 2.

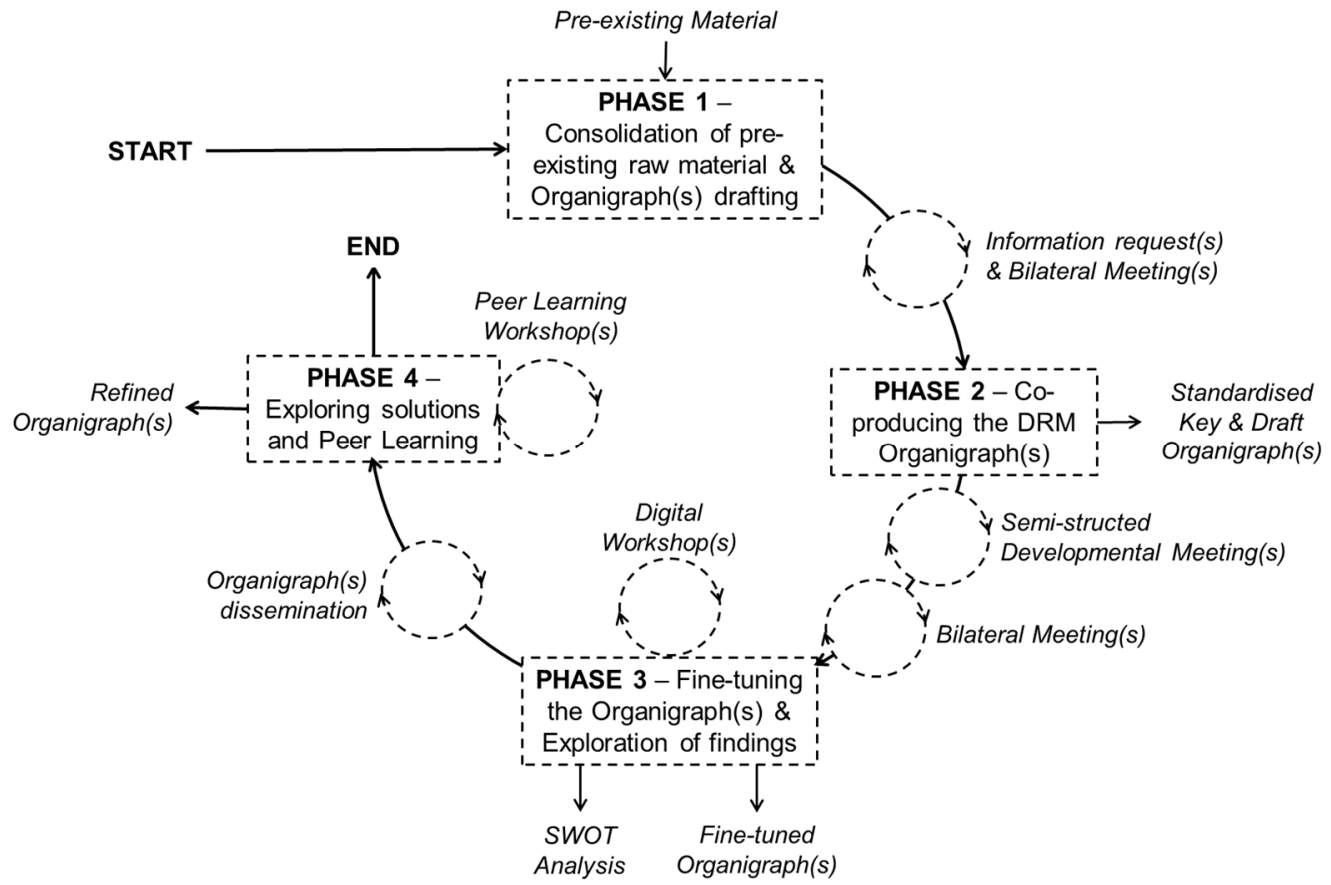

Figure 1. The four iterative phases of the semi-empirical approach used in the co-production of Organigraphs to map DRM governance structures within five $\mathrm{CH}$ sites across Europe.

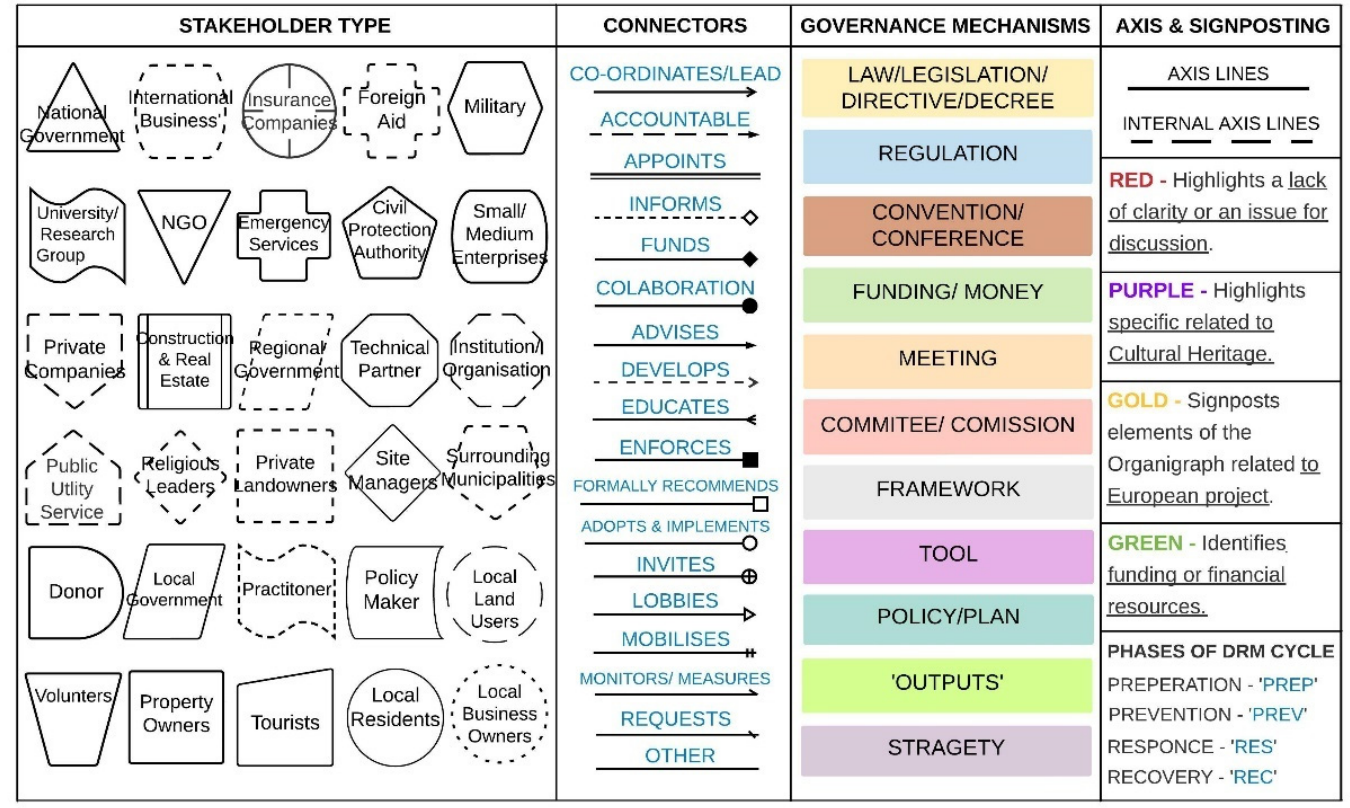

Figure 2. The standardised key used in the co-production of the Organigraphs, adapted from the Organigraph Toolkit created by Tiliouine et al. (2018) to suit $\mathrm{CH}$ and DRM governance requirements.

Phase 2 aimed at enhancing the detail and accuracy of the draft Organigraphs through a collaborative process with the LLC and relevant stakeholder groups. Phase 2 took place between November 2020 and April 2021. To mitigate against attrition and minimise the 
workload for the LLC, each LL had subtly different approaches of co-producing the Organigraphs, which they defined based on their established internal processes. Across the project, the following qualitative methodological approaches were used to enhance the detail of the Organigraphs in Phase 2: 1-h semi-structured developmental meetings between the researcher and LLC in which specific aspects of the Organigraph were discussed and adapted. One to two-hour task group meetings between the researcher and q targeted expert designed to explore their opinion on an aspect of the Organigraph with which they have specialist knowledge or experience. One-hour bilateral stakeholder meetings with a group of associated stakeholders designed to stimulate a discussion around a particularly challenging aspect of the Organigraphs. Finally, simple internal email exchanges in which targeted requests or text-based input would be sufficient. The Organigraphs were transferred into an interactive digital whiteboard using the Lucidchart software to ensure consistency and validity during this phase. This software not only allowed all LLCs and stakeholders to view and interact with the Organigraphs remotely, but it provided an exact record of all refinements made and by whom. The researcher facilitated the refinement of the Organigraphs with monthly email reminders, prompts, and, where possible, made direct edits to the Organigraphs to stimulate developments. The deadline for this phase was April 2021, and the LLC were allowed to dictate when they felt the Organigraphs were ready to move onto the next phase of the semi-empirical approach.

Phase 3 aimed to encourage different LL stakeholders to explicitly validate and finetune the completed Organigraphs. Furthermore, Phase 3 also attempted to facilitate explicit discussions between different stakeholder groups around the strengths, weaknesses, opportunities, and threats perceived within each of the LL own DRM governance structures. To achieve this, 12 remote digital workshops were conducted between May 2021 and July 2021, in accordance with restrictions imposed by the COVID-19 epidemic. The workshops used Microsoft Teams to facilitate the discussions in which the Lucidchart software was used to present the Organigraphs to all participants. Four interactive activities were designed on the digital software 'Miro' to record the stakeholders' perceptions, opinions, and inputs. Where necessary, these comments were then used to make immediate changes to the Organigraphs or develop LL specific governance proposals. Finally, Phase 4 aimed to facilitate peer learning between the different international LL, providing them with the opportunity to critique and learn from the five Organigraphs co-produced through the semi-empirical approach. This was similarly conducted through a remote digital peer learning workshop conducted in September 2021, facilitated through an online Miro board that was used to identify potential synergies between the LLs and facilitate cross-national learning and innovation.

\section{Results}

The results section presents three example Organigraphs co-produced using the above methodology to map the DRM governance within three distinct $\mathrm{CH}$ sites. First, Figure 3 demonstrates the refined version of the Organigraph mapping the DRM governance of the port town of Sığacık in the municipality of Seferihisar, Turkey, in which the Organigraph focuses on the DRM governance around the key hazard of earthquakes. Secondly, Figure 4 demonstrates the refined Organigraph mapping of the DRM governance across the catchment of the Sava River Basin in South-Eastern Europe. Finally, Figure 5 demonstrates the Organigraph created to map the DRM governance for the Isle of Dordrecht located in the Rhine-Meuse delta in the Netherlands. Both Organigraphs focus on the hazard of flooding. It is important to note that the Organigraphs provided in this article should not be considered definitive. They demonstrate simplified DRM governance structures of three LLs as perceived and explored by a sample group of experts within each LL at the end of Phase 3. These Organigraphs have been provided to demonstrate the potential of the technique as a methodology for mapping governance. They should always be considered as continually evolving tools. 


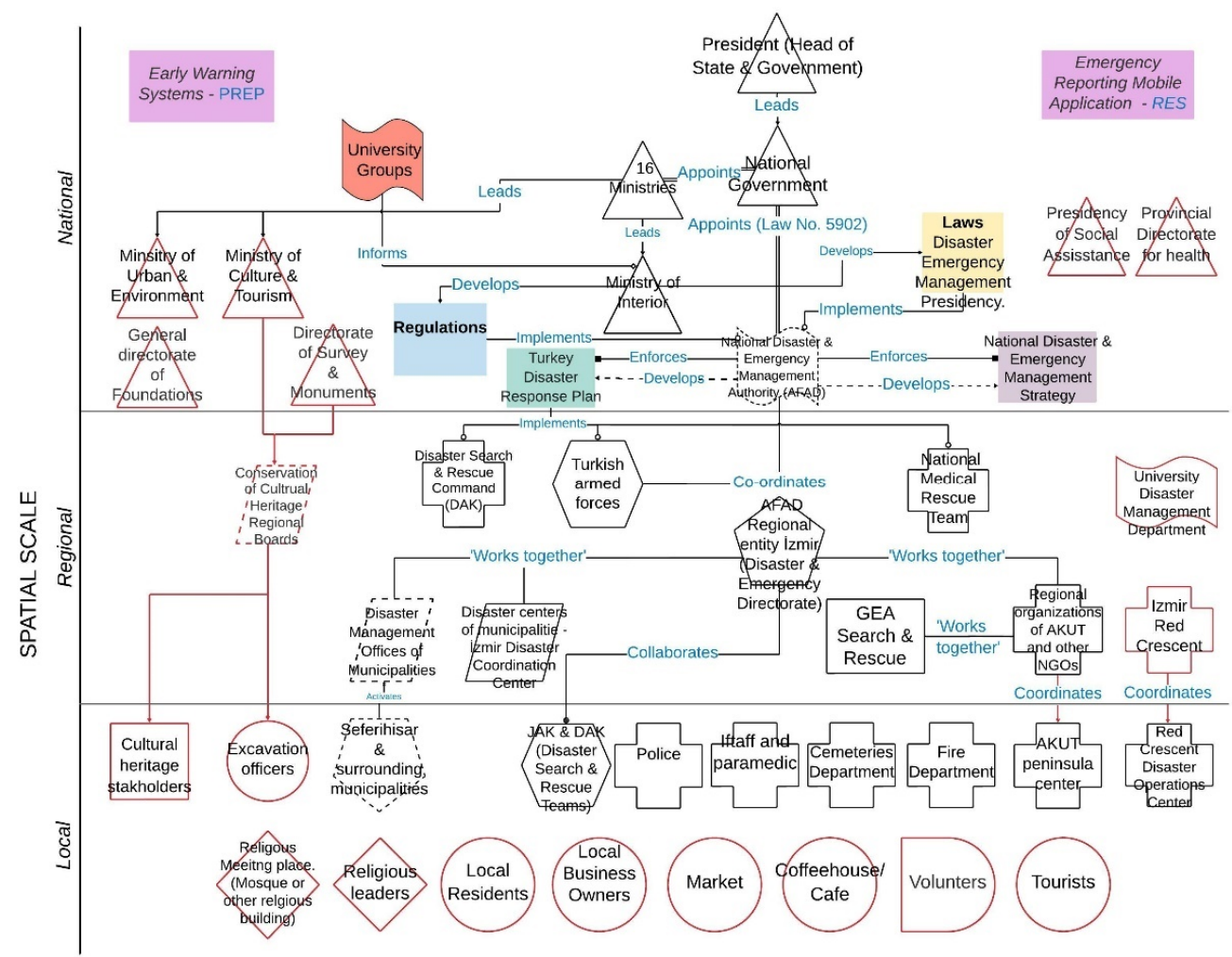

Figure 3. The refined DRM Organigraph for the port town of Sığacık after the stakeholder workshops at the end of Phase 3, August 2021.

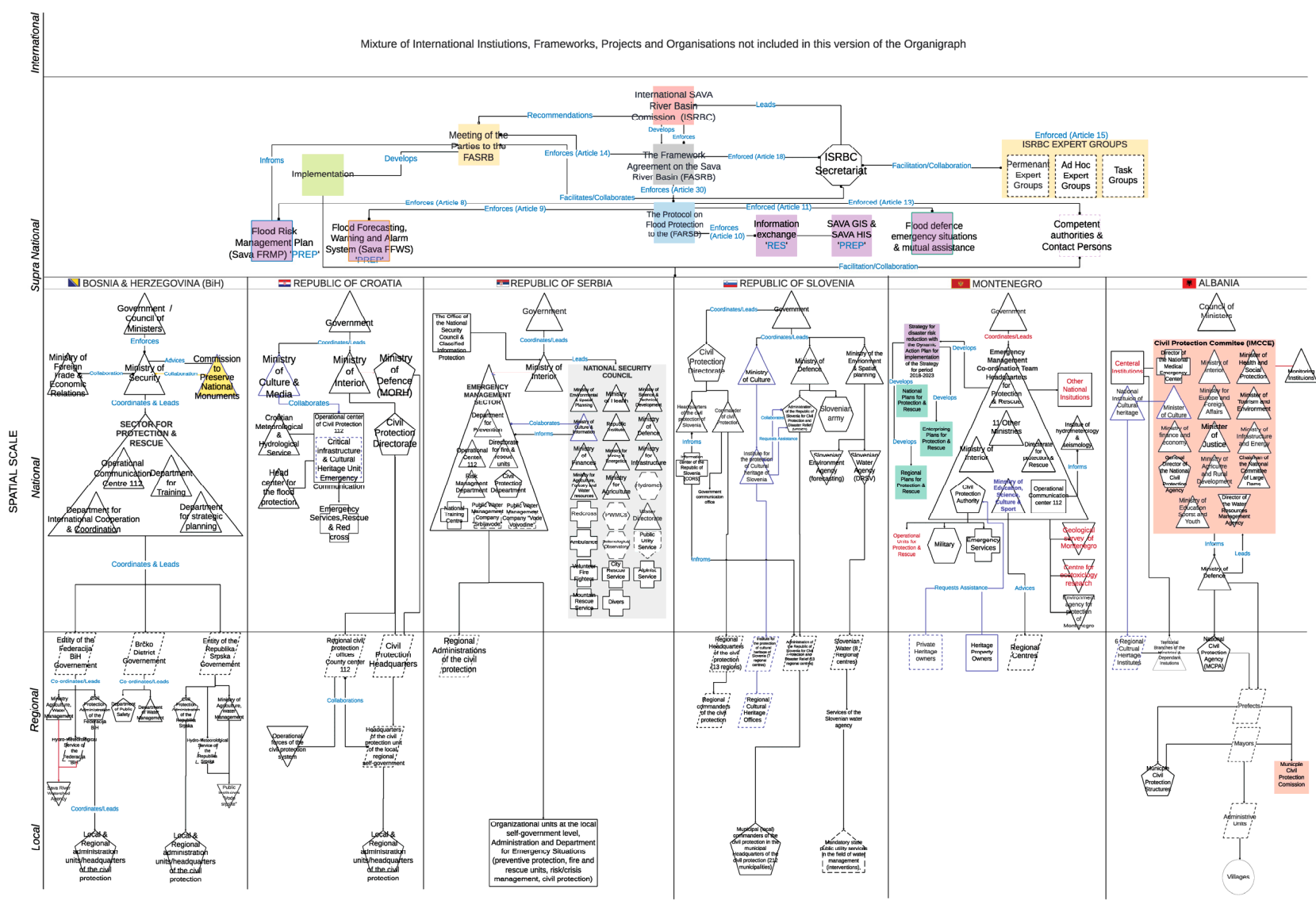

Figure 4. The refined DRM Organigraph for the Sava River Basin after the stakeholder workshops at the end of Phase 3, August 2021. 


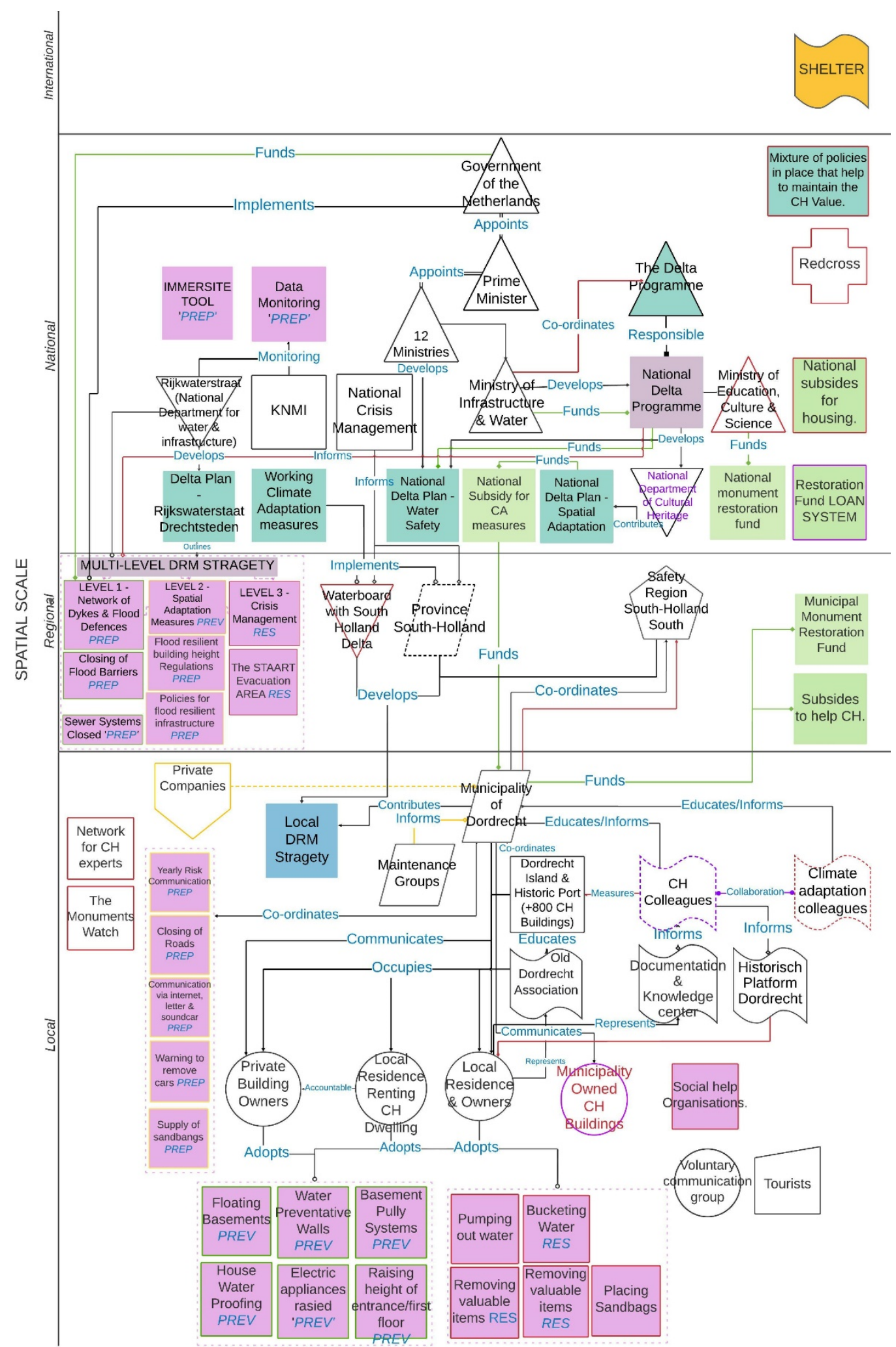

Figure 5. The refined DRM Organigraph for the Isle of Dordrecht located in the Rhine-Meuse delta in the Netherlands after the stakeholder workshops at the end of Phase 3, August 2021.

\section{Discussion}

First, it is important to highlight the success of the Organigraph technique in mapping DRM governance structures. The Organigraph technique provided a simple yet effective tool for a group of interdisciplinary stakeholders to map and explore their DRM governance 
structures, by highlighting the key stakeholder groups, their relationships and governance mechanisms using a standardised set of shapes, colours, and lines arranged on an interactive digital whiteboard. This outcome is evident in the three examples of Organigraphs provided in Figures 3-5, demonstrating three different DRM governance structures across three separate LLs using the same approach. Furthermore, the value of the Organigraphs as a practical tool to help stakeholders map and explore their DRM governance was reinforced in comments by the stakeholders who participated within the LLs. Such as, "It analyses in a simple and clear way the relationships between different entities that have always been very complex" and "It is useful to help identify who is communicating with who". In the development of the Organigraphs, it is important to emphasise the value of the standardised key (Figure 2) both as a flexible but consistent set of building blocks to create Organigraphs. As well as its capacity to provide the researcher and the participants with a 'common language' to explore and analyse the DRM governance across different LL and contexts, which does not require previous knowledge or experience. This common language ensures that regardless of the different social, political, and economic contexts, external variables or potential issues/risks being faced, stakeholders can immediately recognise and engage with other LLs Organigraphs. Importantly, the potential of the Organigraph technique to provide clarity around complex DRM governance directly coincides with the priorities of the SFDRR [13] and may assist in the operationalisation of it in practice.

Building from this, the Organigraph technique within the research project set the foundation for cross-national and cross-issue collaboration. Stakeholders could explore and engage with different DRM governance structures using the Organigraphs as a platform for drawing comparisons between DRM governance arrangements and learn from other $\mathrm{CH}$ sites. An example of this can be seen when comparing the Organigraph developed within the catchment of the Sava River Basin in South-Eastern Europe in Figure 4 and the Isle of Dordrecht located in the Rhine-Meuse delta in the Netherlands in Figure 5. Both LLs focused on the risk of flooding. However, they represent distinctly different $\mathrm{CH}$ sites, governed at different scales, representing urban and natural $\mathrm{CH}$ values within different political contexts and histories. In part, because of the consistency provided by the standardised key, direct comparisons can be drawn between different Organigraphs. For example, both contain similar key stakeholder groups in the form of national ministries, municipal departments and similar connectors linking these entities. However, Figure 5 encapsulates a linear cross-national DRM governance approach in which the international Sava River basin commission (ISRBC) operates as an independent institution at the supranational scale facilitating the coordination and development of a wider range of DRM tools, unlike the DRM governance structure within the Dordrecht LL, which was depicted as a more vertical process capturing a regional focused DRM governance structure situated around a multi-level DRM.

Moving forward, however, the true value of the Organigraph technique goes beyond its ability to provide a simple tool to map the complexities of DRM governance structure, but lies in the iterative phases of the semi-empirical approach used to co-produce them. At its core, the semi-empirical approach provides a platform for the stakeholders to collaboratively explore and critique the strengths, weaknesses, opportunities, and threats within their DRM governance structures.

Through the research approach and co-production of the Organigraphs, the stakeholders who participated demonstrated advanced levels of individual learning and selfreflection. The approach brought to the surface aspects of the DRM governance structures that lacked clarity and required greater discussion and attention. First, the semi-empirical approach highlights, missing stakeholders and connections, weaknesses, opportunity spaces, and avenues of collaboration between different entities or stakeholder groups. Examples of these are represented in Figures 3-5 and highlighted through the colour red as defined in the standardised key (Figure 2). An example of this iterative learning process was observed within the Seferihisar LL, in which it was highlighted that a key stakeholder group had not been previously included in the wider project work in which one expert 
stated, "There were 3 wildfires and 1 earthquake in 1 year and there seems to be a stakeholder gap". Furthermore, the Organigraphs co-produced within the Seferihisar LL stimulated the preliminary process of stakeholder identification and engagement with the local community, in which an array of local community stakeholders and $\mathrm{CH}$ experts were explicitly included in the Organigraph to stimulate a process of integrate them better into the legal DRM framework. In fact, during the semi-empirical approach, the LLC and stakeholders pinpointed various strategies, approaches, and methods to better integrate these local experts. The challenges in mapping stakeholders at the local spatial scale of DRM governance is widely cited across academic literature [18], and there is growing international emphasis on the integration of local communities into traditionally hierarchical DRM governance structures [40-42] and the recognition of the importance of bringing local communities in DRM in enhancing preparedness and resilience [43].

With this in mind, what the example of the Organigraph in Seferihisar provides is the potential of the semi-empirical approach to create a platform for stakeholders to explore the role of different community groups in different phases of DRM and start to map them within the wider DRM governance structure, thereby assigning potential communication channels, responsibilities, and roles to previously undefined actions in the event of a disaster or actions of stakeholders which are outside of the defined legal framework.

Ultimately, the Organigraph technique provides a dynamic, continually evolving document with the ability to capture implicit and explicit decisions within a DRM governance structure and opens greater discussion on the roles, accountability, and responsibilities of different stakeholder groups, in part addressing one of the potential challenges of integrating the SFDRR around accountability [44] as well as pinpointing more adaptive forms of governance within the Organigraph.

Taking this one step further, the development of the Organigraphs through the semiempirical approach facilitated proactive changes by the participants. For example, not only did the stakeholders in the approach identify missing stakeholder groups, but in one case, the experts involved in the semi-empirical approach took an active decision in response to the findings in the context of the wider research project. For instance, experts from the Ministry of Security in Bosnia and Herzegovina (Figure 4) observed the absence of $\mathrm{CH}$ stakeholders in the DRM governance and opened a dialogue with experts at the Commission to Preserve National Monuments, and requested to include this new connection into their Organigraph. What this would suggest is that the Organigraphs not only pinpoint missing information but can encourage experts to act based on the findings.

Furthermore, these findings can be actively updated to highlight new connections as part of the semi-empirical process. Building upon this, stakeholders from the catchment of the Sava River Basin in South-Eastern Europe used the Organigraphs to highlight wider governance issues around the "Overlapping competencies" between some stakeholder groups and the potential "Poor communication between the institutions $\mathcal{E}$ professional services of the entities". What this indicates is that the Organigraph technique not only yields self-reflection about the stakeholders involved (or not) in DRM governance but, also, highlights broader governance issues around the function/role of stakeholders within that DRM governance structure and the lack of communication between them.

Finally, it is important to temper the expectations of the Organigraph technique. While it did indeed provide a valuable tool in the mapping of key stakeholders, governance mechanisms, and their connections, facilitating broader discussion and debate around those governance structures, there were limitations to the approach. First, it was a constant challenge to find the balance between complexity and clarity. A common criticism from some of the stakeholders across the LL was that if you are unfamiliar with the Organigraph, it can be overwhelming. Alternatively, in comparison, one of the stakeholders who participated in Phase 3 of the approach developing the Organigraph for the port town of Sıgacık lamented that in its current form, the Organigraph could be considered an "oversimplification" of the DRM governance structure, which does not reflect the complexity of connections between different stakeholders and the diversity in the DRM governance. 
Secondly, one stakeholder contributing to the validation of the Organigraph within Dordrecht stated that "Quality of the tool was dependent on the quality of the inputs $\mathcal{E}$ it is a 'temporary representation' of the DRM governance"; this was support be the overall outcome of the work in which two of the Organigraphs had to be redefined during the research approach based on the developed of new policy. Governance is a continually evolving entity, and as such, the Organigraphs are hard to keep updated.

Finally, one stakeholder who contributed to the validation of the Organigraph within the Sava River basin stated that "The Organigraphs show what happens in theory, but in practice it can be different". This comment opens an extremely interesting topic for further discussion, considering the role of pre-existing inter-mutual relations between partners when dealing with a crisis. Organigraphs are dedicated to binding trust and knowledge relations between partners. Still, we did not have the opportunity to test the effects of such pre-established relations during an actual disaster.

\section{Conclusions}

The Organigraph technique has the potential to be an innovative and collaborative tool for practitioners, policymakers, and academics alike. Using a standardised key, different DRM governance structures can be mapped, compared, and explored regardless of their context or subjective variables. This provides a mechanism for the mapping and exploration of DRM governance, which may in turn aid in the operationalisation of the SFDRR by enhancing clarity around DRM governance and strengthening disaster preparedness. Furthermore, the potential of the Organigraph technique can be maximised through the use of a transdisciplinary semi-empirical approach in which a transdisciplinary stakeholders can come together to discuss and co-produce a map of the DRM governance. Pinpointing theirs (and others) competencies, roles, and responsibilities.

Through the semi-empirical approach, the different stakeholders involved in the Organigraphs development are encouraged to continuously reflect on their own DRM governance structures through two different mechanisms. First, through a process of selfcritique and reflection in which the stakeholders are encouraged to see weaknesses, bottle necks, and limitations of their own DRM governance structures before a disaster event, in turn stimulating proactive action to mitigate against the potential effects of these disasters in the preparedness and prevention phases of the DRM cycle. Secondly, through the utilisation of the standardised key the Organigraphs provide a platform for cross-nation, cross-issue comparison in which experts can quickly recognise and unpack DRM governance structures of completely different contexts. The ability of experts to quickly understand and learn from different DRM governance provides a mechanism to facilitate learning across different $\mathrm{CH}$ sites and a mechanism for peer-leaning between different expertise.

Finally, this article presents the initial application of the Organigraph technique within the context of DRM governance $\mathrm{CH}$. As a result, further testing and application of the semi-empirical approach and the tool would be required before a complete understanding of its potential value can be understood. Furthermore, there were limitations to the approach that require further research and development to maximise on its potential including. Critically, it is also important to highlight that the Organigraphs as maps of DRM governance structures should not necessarily be considered as guides used to outline the explicit decision-making processes each stakeholder should make in the event of a disaster, but rather as an iterative learning tool designed to facilitate discussion, highlight weakness, and provide the basis for a more effective DRM in crisis situations.

Author Contributions: Conceptualisation, L.J.D. and A.N.V.; methodology, L.J.D. and M.S.; validation, M.S. and D.B.; formal analysis, L.J.D.; investigation, M.S., and D.B.; data curation, L.J.D.; writing—original draft preparation, L.J.D., J.T.; writing—review and editing, L.J.D., A.N.V., J.T., M.S. and D.B.; visualisation, L.J.D.; supervision, J.T. All authors have read and agreed to the published version of the manuscript. 
Funding: This research was funded by a European Union Horizon 2020 grant (821282). The SHELTER project website is: shelter-project.com (9 December 2021).

Institutional Review Board Statement: Not applicable.

Informed Consent Statement: Not applicable.

Data Availability Statement: Not applicable.

Acknowledgments: This research has been supported by the SHELTER project, funded by a European Union Horizon 2020 grant (821282). The SHELTER project website is: https:/ / shelter-project.com/ (accessed on 9 December 2021). We would wish to thank all the members of the Open Labs (Living Labs) who actively contributed to the development of Organigraphs throughout the project. We would also like to thank the anonymous referees for their constructive comments and suggestions that led to improve the overall quality of the paper.

Conflicts of Interest: The authors declare no conflict of interest.

\section{References}

1. Araoz, G.F. Preserving heritage places under a new paradigm. J. Cult. Herit. Manag. Sustain. Dev. 2011, 1, 55-60. [CrossRef]

2. Szmelter, I. New Values of cultural heritage and the need for a new paradigm regarding its care. CeROArt 2013. [CrossRef]

3. Wiktor-Mach, D. Cultural heritage and development: UNESCO's new paradigm in a changing geopolitical context. Third World Q. 2018, 40, 1593-1612. [CrossRef]

4. Sabbioni, C.; Cassar, M.; Brimblecombe, P.; Lefevre, R.A. Vulnerability of the Worlds Cultural Heritage to Climate Change. Council of Europe, 2009. Available online: https://www.coe.int/t/dg4/majorhazards/activites/2009/Ravello15-16may09/ Ravello_APCAT2008_44_Sabbioni-Jan09_EN.pdf (accessed on 29 November 2021).

5. Ilieș, D.C.; Caciora, T.; Herman, G.V.; Ilieș, A.; Ropa, M.; Baias, Ș. Geohazards affecting cultural heritage monuments. A complex case study from Romania. Geo J. Tour. Geosites 2020, 31, 1103-1112. [CrossRef]

6. Ravankhah, M.; Chmutina, K.; Schmidt, M.; Bosher, L. Integration of Cultural Heritage into Disaster Risk Management: Challenges and Opportunities for Increased Disaster Resilience. In Going Beyond; Springer: Cham, Switzerland, 2017; pp. 307-321. [CrossRef]

7. Petti, L.; Trillo, C.; Makore, B.N. Cultural Heritage and Sustainable Development Targets: A Possible Harmonisation? Insights from the European Perspective. Sustainability 2020, 12, 926. [CrossRef]

8. Sabatini, F. Culture as Fourth Pillar of Sustainable Development: Perspectives for Integration, Paradigms of Action. Eur. J. Sustain. Dev. 2019, 8, 31-40. [CrossRef]

9. Nocca, F. The Role of Cultural Heritage in Sustainable Development: Multidimensional Indicators as Decision-Making Tool. Sustainability 2017, 9, 1882. [CrossRef]

10. Stanton-Geddes, Z.; Soz, S.A. Promoting Disaster Resilient Cultural Heritage; World Bank: Washington, DC, USA, 2017; Available online: https:/ / openknowledge.worldbank.org/handle/10986/28955 (accessed on 5 December 2021).

11. Garcia, B.M. Resilient cultural heritage: From global to national levels-the case of Bhutan. Disaster Prev. Manag. 2019, 29 , 36-46. [CrossRef]

12. Wahlström, M. New Sendai Framework Strengthens Focus on Reducing Disaster Risk. Int. J. Disaster Risk 2015, 6, 200-210. [CrossRef]

13. United Nations Office for Disaster Risk Reduction (UNDRR). Sendai Framework for Disaster Risk Reduction 2015-2030. Available online: https://www.undrr.org/publication/sendai-framework-disaster-risk-reduction-2015-2030 (accessed on 26 November 2021).

14. Mizutori, M. Reflections on the Sendai Framework for Disaster Risk Reduction: Five Years Since Its Adoption. Int. J. Disaster Risk Sci. 2020, 11, 147-151. [CrossRef]

15. Lindner, R.; Lückerath, D.; Milde, K.; Ullrich, O.; Maresch, S.; Peinhardt, K.; Latinos, V.; Hernantes, J.; Jaca, C. The Standardization Process as a Chance for Conceptual Refinement of a Disaster Risk Management Framework: The ARCH Project. Sustainability 2021, 13, 12276. [CrossRef]

16. Rosa, A.; Santangelo, A.; Tondelli, S. Investigating the Integration of Cultural Heritage Disaster Risk Management into Urban Planning Tools. The Ravenna Case Study. Sustainability 2021, 13, 872. [CrossRef]

17. Giuliani, F.; Grazia De Paoli, R.; Di Miceli, E. A risk-reduction framework for urban cultural heritage: A comparative study on Italian historic center. J. Cult. Herit. Manag. Sustain. Dev. 2021, 11, 499-515. [CrossRef]

18. Djalante, R.; Lassa, S. Governing complexities and its implication on the Sendai Framework for Disaster Risk Re-duction priority 2 on governance. Prog. Disaster Sci. 2019, 2, 100010. [CrossRef]

19. Gall, M.; Nguyen, K.H.; Cutter, S.L. Integrated research on disaster risk: Is it really integrated? Int. J Disaster Risk Reduct. 2015, 12, 255-267. [CrossRef]

20. Salim Uddin, M.; Emdad Haque, U.; Nuruzzaman Khan, M. Good governance and local level policy implementation for disasterrisk-reduction: Actual, perceptual, and contested perspectives in coastal communities in Bangladesh. Disaster Prev. Manag. 2020, 30, 94-111. [CrossRef] 
21. Peduzzi, P. The Disaster Risk, Global Change, and Sustainability Nexus. Sustainability 2019, 11, 957. [CrossRef]

22. Albris, K.; Lauta, K.C.; Raju, E. Strengthening Governance for Disaster Prevention: The Enhancing Risk Management Capabilities Guidelines. Int. J. Disaster Risk Reduct. 2020, 47, 101647. [CrossRef]

23. Jigyasu, R. Chapter 3-Mainstreaming cultural heritage in disaster risk governance. In Strengthening Disaster Risk Governance to Manage Disaster Risk; Elsevier: Amsterdam, The Netherlands, 2021; pp. 21-26.

24. Behnassi, M.; Gupta, H.; El Haiba, M.; Ramachandran, G. Effectiveness of Disaster Risk Governance and Resilience Building: Linkages, Knowledge, Inclusiveness, and Regulation. In Social-Ecological Systems (SES); Springer: Cham, Switzerland, $2021 ;$ pp. 1-37. [CrossRef]

25. Manyena, B. After Sendai: Is Africa Bouncing Back or Bouncing Forward from Disasters. Int. J. Disaster Risk Sci. 2016, 7, 41-53. [CrossRef]

26. Goniewicz, K.; Burkle, F.M. Challenges in Implementing Sendai Framework for Disaster Risk reduction in Poland. Int. J. Environ. Res. Public Health 2019, 16, 2574. [CrossRef]

27. Brumann, C. Cultural Heritage. In International Encyclopedia of the Social E Behavioral Sciences, 2nd ed.; Elsevier: Amsterdam, The Netherlands, 2015.

28. Ginzarly, M.; Teller, J. Eliciting cultural heritage values: Landscape preferences versus representative images of the city. J. Cult. Herit. Manag. Sustain. Dev. 2018, 8, 257-275. [CrossRef]

29. Hajialikhani, M. A Systematic Stakeholders Management Approach for Protecting the Spirit of Cultural Heritage Sites. In Proceedings of the 16th ICOMOS General Assembly and International Symposium: Finding the Spirit of Place-Between the TANGIBLE and the Intangible, Quebec, QC, Canada, 29 September-4 October 2008. Available online: http:// openarchive.icomos. $\mathrm{org} / \mathrm{id} /$ eprint/41/ (accessed on 30 November 2021).

30. Caciora, T.; Herman, G.V.; Ilies, A.; Baias, Ș.; Ilies, D.C.; Josan, I.; Hodor, N. The Use of Virtual Reality to Promote Sustainable Tourism: A Case Study of Wooden Churches Historical Monuments from Romania. Remote Sens. 2021, 13, 1758. [CrossRef]

31. Teutonico, J. Management Planning for Archaeological Sites: An International Workshop Organised by the Getty Conservation Institute and Loyola Marymount University, 19-22 May 2002, Corinth, Greece; The Getty Conversion Institute: Los Angeles, CA, USA, 2002.

32. Munene, M.B. Adaptive governance as a catalyst for transforming the relationship between development and disaster risk through the Sendai Framework? Int. J. Disaster Risk Reduct. 2018, 28, 653-663. [CrossRef]

33. Bello, O.; Bustamante, A.; Pizarro, P. Planning for Disaster Risk Reduction within the Framework of the 2030 Agenda for Sustainable Development, Project Documents (LC/TS.2020/108) Santiago, Economic Commission for Latin America and the Caribbean (ECLAC). 2021. Available online: https://repositorio.cepal.org/bitstream/handle/11362/46639/1/S2000452_en.pdf (accessed on 30 November 2021).

34. Holguín-Veras, J.; Jaller, M.; Van Wassenhove, L.N.; Pérez, N.; Wachtendorf, T. On the unique features of post-disaster humanitarian logistics. J. Oper. Manag. 2012, 30, 494-506. [CrossRef]

35. Mechler, R. Reviewing estimates of the economic efficiency of disaster risk management: Opportunities and limitations of using risk-based cost-benefit analysis. Nat Hazards 2016, 81, 2121-2147. [CrossRef]

36. Heo, B.-Y.; Heo, W.-H. Economic Analysis of Disaster Management Investment Effectiveness in Korea. Sustainability $2019,11,3011$. [CrossRef]

37. Sutton-Grier, A.E.; Gittman, R.K.; Arkema, K.K.; Bennett, R.O.; Benoit, J.; Blitch, S.; Burks-Copes, K.A.; Colden, A.; Dausman, A.; DeAngelis, B.M.; et al. Investing in Natural and Nature-Based Infrastructure: Building Better Along Our Coasts. Sustainability 2018, 10, 523. [CrossRef]

38. Mintzberg, H.; Van der Heyden, L. Organigraphs: Drawing how companies really work. Harv. Bus. Rev. 1999, 77, 87-94.

39. Tiliouine, A.; Kosinska, M.; Schröder-Bäck, P. Tool for Mapping Governance for Health and Well-Being: The Organigraph Method. Governance for Health and Well-Being Programme Division of Policy and Governance for Health and Well-Being WHO Regional Office for Europe 2018. Available online: https:/ / www.euro.who.int/_data/assets/pdf_file/0011/389999/20181218-h1015toolkit.pdf (accessed on 30 November 2021).

40. Makaya, E.; Rohse, M.; Day, R.; Vogel, C.; Mehta, L.; McEwen, L.; Rangecroft, S.; Van Loon, A.F. Water governance challenges in rural South Africa: Exploring institutional coordination in drought management. Water Policy 2020, 22, 519-540. [CrossRef]

41. Ashu, R.E.A.; Van Niekerk, D. Building national and local capacity for disaster risk management in Cameroon. Disaster Prev. Manag. 2020, 29, 457-470. [CrossRef]

42. Amaratunga, D.; Malalgoda, C.; Haigh, R.; De Silva, A. How Do We Organise for Disaster Risk Reduction and Resilience? A Study on Disaster Risk Governance in Sri Lanka. University of Huddersfield. Available online: https://huddersfield.box.com/s/ zwtx3jrn78gmobm62zcxgob8o875qvwa (accessed on 2 December 2021).

43. Allen, K.M. Community-based disaster preparedness and climate adaptation: Local capacity-building in the Philippines. Disaster 2006, 30, 81-101. [CrossRef] [PubMed]

44. Raju, E.; da Costa, K. Governance in the Sendai: A way ahead? Disaster Prev. Manag. 2018, 27, 278-291. [CrossRef] 